\title{
Application of Co-Ni-P coating on grain-oriented electrical steel
}

\author{
Vishu Goel ${ }^{1}$, Philip Anderson ${ }^{1}$, Jeremy Hall ${ }^{1}$, Fiona Robinson ${ }^{2}$ and Siva Bohm ${ }^{3}$ \\ ${ }^{1}$ Wolfson Centre for Magnetics, Cardiff University, Cardiff CF243AA, UK \\ ${ }^{2}$ Cogent Power, Newport, Gwent NP19 0RB, UK \\ ${ }^{3}$ Tata Steel RD\&T, Rotherham S603AR, UK
}

\begin{abstract}
An electroless plating of Co-Ni-P was applied to a grain-oriented electrical steel substrate resulting in a power loss improvement of approximately 9-11\%. The mean thickness of the coating was found to be $2.15 \pm 0.15 \mu \mathrm{m}$ from Environmental Scanning Electron Microscope (ESEM) images. Shifts of the magnetostriction stress sensitivity curves showed that stress was acting on the substrate corroborated by a shift in X-ray Diffraction (XRD) peaks and narrowing of the domains after the samples were coated. The magnetic property measurement system (MPMS) results confirmed the magnetic nature of the coating and XRD results showed peaks of $\alpha$-Iron in uncoated sample, $\alpha$-Iron-Cobalt and $\alpha$-Iron in Co-Ni-P coated sample. The Talysurf profilometer showed a decrease in surface roughness (Ra) values after coating the sample which reduced the hysteresis loss.
\end{abstract}

Index Terms - Power loss, Magnetostriction, Electroless coating, Stress, magnetic coating, Grain oriented electrical steel

\section{INTRODUCTION}

$\mathrm{E}$ fforts are being made to produce high performance electrical steels through several methods including better secondary recrystallization methods [1], grain orientation control [2], increasing the electrical resistivity, gauge reduction [3] and understanding the magnetic domain structure [4-7] Perhaps the greatest gains can be made by employing effective stress coatings $[8,9]$ which can play a dominant role in minimizing losses and magnetostriction.

The stress can be applied to the material with the help of coatings. Coating the steel helps in reducing both the losses and the magnetostriction. It is well known that the effect of magnetostriction can be suppressed by the application of tensile stresses. Tensile stress imparted from the coating on the steel sheet eliminates the surface closure domains and losses are reduced as tensile stress helps in narrowing the domain wall spacing in addition to minimizing the circulation of eddy currents by providing electrical insulation. Current coating systems on grain oriented electrical steel comprise of a two layer coating with a forsterite layer $\left(\mathrm{Mg}_{2} \mathrm{SiO}_{4}\right)$ below an aluminum orthophosphate layer. Conventionally, coatings which have low coefficient of thermal expansion are used as when cooled from high temperature they contract less than the substrate. This difference in cooling applies a tensile stress on the substrate.

There are a number of different methods that can be used to apply a coating on the surface of steel sheet such as sol gel [10], chemical vapor deposition [11], physical vapor deposition [12], plasma spraying, wet coating, printing, electroless plating and electro chemical.

This paper describes an investigation of electroless plating of Co-Ni-P which has the advantages of corrosion resistance, uniform thickness, wear and abrasion resistance. Stresses develop in electroless plating and are generated either due to difference in the coefficient of thermal expansion between the substrate and the coating or develops in the deposition process. During deposition the particles deposit at few places rather than forming a uniform atomic layer. The coating grows at those few places only. The surface tension binds the particles together. Rearrangement of these atoms due to surface tension changes the interatomic distance and hence develop tensile or compressive stress depending on the increase or decrease in the interatomic distance. Minimizing the coagulation could reduce the amount of tensile stress and by introducing phosphorus the stress can be changed from tensile to compressive as can be seen in the figure 1 [13]. The electroless deposition rates are very fast as compared to other chemical coating techniques and being autocatalytic no external current is supplied for the process to take place.

Chivavibul et al. [14] produced an electroless Ni-Co-P coating of 1 micron thickness on non-oriented electrical steel and found that the coating was effective in reducing losses by up to $4 \%$ at a magnetic flux density of $0.3 \mathrm{~T}$ and frequency of $400 \mathrm{~Hz}$. The coating was able to minimize the eddy current loss at higher frequencies to reduce the overall loss. Power transformers operate at a flux density of $1.5 \mathrm{~T}$ and above and a frequency of $50 \mathrm{~Hz}$. The component of eddy current loss decreases as the frequency decreases. It was also found that as the thickness of Ni-Co-P coating increased, hysteresis loss increased and hence Ni-Co-P may not be suitable at lower frequencies where hysteresis and anomalous loss dominate [15]. Co-Ni-P was chosen as a suitable coating. The amount of phosphorus could be balanced to develop compressive stress in the coating. The coating is also ferromagnetic and its properties can be altered by varying the chemical content. The parameters used to deposit the Co-Ni-P coating determine the impact on final magnetic properties such as the coercivity and hysteresis loss [16]. The aim of this paper is to evaluate and optimize these coatings for transformer applications and compare them to conventional coatings.

\section{MATERIAL AND METHODS}

Grain oriented $(\mathrm{Fe}-3 \% \mathrm{Si})$ samples $(0.3 \mathrm{~mm}$ x $30 \mathrm{~mm} \quad \mathrm{x}$ $305 \mathrm{~mm}$ ) were supplied by Cogent Power Ltd., Newport and both the tension and insulation coating were removed with a solution of $7.5 \%$ sulphuric acid $+1 \%$ Hydrofluoric acid for approximately 10 minutes and then in $4 \%$ Nitric acid solution for approximately 7 minutes. The specific total loss was measured with a single strip tester (SST) [17] from a magnetic flux density of $1.1 \mathrm{~T}$ to $1.7 \mathrm{~T}$ at a frequency of $50 \mathrm{~Hz}$. Flux closure was provided by a pair of high permeability wound 
yokes with a $255 \mathrm{~mm}$ pole gap and the number of turns on the primary and secondary windings were 865 and 250 respectively. A mutual inductor was used to provide air flux compensation. The magnetostriction measurements were made on a magnetostriction measurement system using the procedure described in[18]. Measurement of stress induced by the coating was also calculated from the measured magnetostriction curves using the method outlined in [18]. The microscopy images were obtained from a XL30 ESEM Field Emission Gun (FEG). The elemental analysis was performed with an Oxford Instruments Energy-dispersive Xray spectroscopy (EDX) analysis system. To study the structure and phases of the coating, XRD was carried out with cobalt radiation at $30 \mathrm{kV}$ and $40 \mathrm{~mA}$.The magnetic domains were imaged with a magnetic pattern viewer[19]. The magnetic properties of the coating were measured at room temperature by MPMS. The magnetic field was applied up to 20000 Oe. The surface roughness of the uncoated and coated surfaces was measured by Talysurf surface profilometer. The measurement was made in the direction of rolling for a distance of $40 \mathrm{~mm}$ for all the samples. The samples were coated with Co-Ni-P using electroless plating. The composition of the bath and the operating conditions were referred from[20] and modified as shown in the table I. To study the effect of coating thickness on the substrate, four samples were immersed in the plating solution and were removed at 20,35, 50, and $90 \mathrm{~min}$ respectively. The $\mathrm{pH}$ of the solution was maintained by adding ammonium hydroxide. To ascertain the effect of $\mathrm{pH}$ on the power loss, five samples were prepared with $\mathrm{pH}$ values varying from 7.8 to 9.4. All five samples were immersed for 90 min duration as it was found to be the optimized time for best results.

\section{RESULTS AND DISCUSSION}

1) Power Loss Results for Various Thicknesses

Figure 2 presents the difference in power loss of the coated and uncoated samples for different time. The uncoated power loss was different for different strips because the Epstein strips cut from a sheet material show a significant local variation in grain size, orientation and pinning sites. The thickness of the coating deposited was proportional to the time for which the samples were kept in the plating solution. The dehydrogenation of hypophosphite provides the hydride ion (1a). The deposition of nickel and cobalt on the surface of grain-oriented electrical steel was triggered by the reduction of nickel and cobalt ions by the hydride ion as shown in reactions (1b) \& (1c) [21]. These deposited particles act as nucleation sites for further deposition of coating and hence the time period of coating dictates the thickness of coating deposited.
$\mathrm{H}_{2} \mathrm{PO}_{2}^{-}+\mathrm{H}_{2} \mathrm{O} \rightarrow \mathrm{H}^{+}+\mathrm{HPO}_{3}{ }^{2-}+2 \mathrm{H}$
$\mathrm{Ni}^{2+}+2 \mathrm{H} \rightarrow \mathrm{Ni}^{0}+2 \mathrm{H}^{+}$
$\mathrm{Co}^{2+}+2 \mathrm{H} \rightarrow \mathrm{Co}^{0}+2 \mathrm{H}^{+}$

Figure 2(a-d) shows that the coating thickness plays a major role in determining the power loss with a thicker coating applying greater stress. For the sample coated for $20 \mathrm{~min}$ the reduction in power loss was around 4-5\%. Material coated for 90 minutes had a reduction in loss of approximately $9-11 \%$ at $1.5 \mathrm{~T}$ as compared to the uncoated sample. The values of stress calculated for 20 and 90 min coated samples were 0.86 $\mathrm{MPa}$ and 2.10 MPa respectively. Song et al. [22] had shown that stress was introduced in the substrate by the Ni-P coating,
The stress can be tensile or compressive depending upon the amount of phosphorus in the coating. 8.5 \% Phosphorus induces compressive stress in the coating[23]. The phosphorus gets trapped during the deposition and forms small grains mono domains increasing the soft magnetic properties [24]. In this case the stress in the coating was compressive as the amount of phosphorus was confirmed to be between $9-10 \%$ and hence tensile stress acted on the substrate which was beneficial in terms of power loss reduction and magnetostriction. To minimize losses, coating thickness could be increased but the stress decreases as the thickness increases [23] also it leads to unacceptable degradation of permeability shown in figure 3 where the Bpk (magnetic flux density at $800 \mathrm{~A} / \mathrm{m}$ magnetic induction) was reduced after coating and stacking factor gets affected.

2) Magnetic Properties

Figure 4 shows a classical hysteresis loop for Co-Ni-P coating at a $\mathrm{pH}$ of 9.0. The B-H loop measured in the MPMS validates the magnetic nature of the coating. The coercivity of the coating was calculated to be $796 \mathrm{~A} / \mathrm{m}$. The saturation magnetization of the coating was calculated to be $0.0036 \mathrm{emu}$ as compared to $0.0288 \mathrm{emu}$ for grain oriented electrical steel considering same volume for both materials. The magnetic property of Co-Ni-P coating increases the stacking factor by adding a soft magnetic material in the transformer core as compared to the conventional non-magnetic coating.

3) Magnetostriction

Figure 5 shows the magnetostriction curve for the uncoated and Co-Ni-P coated sample for 90 min duration at a $\mathrm{pH}$ of 9.0. The threshold (point of zero magnetostriction) for uncoated and Co-Ni-P coated sample was around $-1 \mathrm{MPa}$ and $-3 \mathrm{MPa}$ respectively. A stress shift of $1.80 \pm 0.20 \mathrm{MPa}$ was observed after coating the sample. This shift in the magnetostriction curve towards the left infers that a significant amount of stress was acting on the substrate. Applying a compressive coating on the substrate eliminates the surface closure domains. These surface closure domains are responsible for magnetostriction [18]. As the surface closure domains are minimized, the magnetostriction reduces.

\section{4) Scanning Electron Microscopy}

Figure 6 shows the SEM image of the 90 min coated sample at a $\mathrm{pH}$ value of 9 . The grey area shows the substrate while the lighter area shows the coating. The coating was uniformly distributed across the sample. No gaps or cracks were found. The thickness of the coating was averaged to be around $2.15 \pm 0.15 \mu \mathrm{m}$.

The stacking factor calculated for $2 \mu \mathrm{m}$ thick coating was $98.68 \%$ as compared to $97.4 \%$ for $4 \mu \mathrm{m}$ thick conventional coating calculated as shown below.

$$
\text { stacking factor }=\left(1-\frac{\text { Non-magnetic material in the core }}{\text { Total material in the transformer }}\right) * 100
$$

If the coating was non-magnetic, the thickness of coating on both sides $=4$ micron

The thickness of Epstein strip without coating $=300$ micron Total material in the transformer core $=304$ micron

$$
\begin{aligned}
& \text { stacking factor }(\%)=\left(1-\frac{300}{304}\right) * 100 \\
& \text { stacking factor }(\%)=98.68
\end{aligned}
$$


But as the coating was also magnetic, it would contribute to the stacking factor hence the new value of stacking factor considering the saturation magnetization of $\mathrm{Co}-\mathrm{Ni}-\mathrm{P}$ coating to be $0.0036 \mathrm{emu}$ and that of GOES to be 0.0288 emu was 98.84 $\%$ as shown below. The increase in stacking factor by the magnetic nature of the coating was found to be insignificant.

$$
\begin{aligned}
& \text { Magnetic contribution of coating to GOES }=\frac{0.0036}{0.0288} * 100 \\
& \text { Magnetic contribution of coating to GOES }=12.5 \% \\
& \text { New stacking factor }(\%)=98.68+\left(\left(\frac{100-98.68}{100}\right) * 12.5\right. \\
& \text { New stacking factor }(\%)=98.84
\end{aligned}
$$

Figure 7 shows five SEM images of the samples prepared with coating of various $\mathrm{pH}(7.8,8.2,8.6,9$ and 9.4). The $\mathrm{pH}$ plays a major role in determining the type of coating (hard or soft magnetic) and controls the coating mechanism[25]. At $\mathrm{pH}$ value of 1.5 the coating was found to be having a coercivity of $11937 \mathrm{~A} / \mathrm{m}$ and at $3.5 \mathrm{pH}$ value the coating had a coercivity of $47747 \mathrm{~A} / \mathrm{m}[24,26]$. As can be seen from the images at a $\mathrm{pH}$ of 7.8 the Co-Ni-P coating coagulates in some areas rather than forming a uniform coating. The nucleation of $\mathrm{Ni}$ and $\mathrm{Co}$ on the surface of grain-oriented electrical steel is not distributed throughout the sample; instead the metal particles nucleate at a few sites. The coating grows at those sites only. The surface tension binds the particle together and changes the interatomic spacing. The change in interatomic spacing introduces tensile or compressive stress in the coating [13]. A reduction in interatomic spacing would lead to a compressive stress in the coating and therefore a tensile stress in the substrate. As the $\mathrm{pH}$ of the solution was increased there was a reduction in size of the particles and a more uniform coating was formed. At a pH of 9 nucleation occurs throughout the sample and we could see a uniform coating on the substrate and a minimal amount of coagulation in the coating. The stress applied by the coating on the substrate was uniform and a reduction in power loss was observed. The $\mathrm{pH}$ was increased further and the coating was again found to be coagulated at various places.

5) Surface profiling

The surface roughness values in figure 8 validate the SEM results. The value of roughness was largely dependent on the $\mathrm{pH}$ of the coating solution. The surface of the sample coated with a $\mathrm{pH}$ value of 7.8 was found to be rougher than the uncoated sample. The least value of roughness was measured at a $\mathrm{pH}$ of 9.0. The surface roughness effects the hysteresis loss [27]. The increase in surface roughness increases the number of free poles on the surface and these free poles pins the domain walls. It leads to reduction of domains and the motion of domain wall is inhomogeneous[9]. Energy is dissipated in freeing these domain walls and this energy contributes to specific total loss. It was assumed that the enhancement of magnetic properties at $\mathrm{pH}$ of 9.0 was due to the improvement in surface roughness by magnetically active coating.

6) Effect of pH on coating composition and power loss

Figure 9 shows the power loss results of the different samples. As expected and endorsed by the SEM images the sample coated with a $\mathrm{pH}$ of 9 shows the highest reduction in power loss because a uniform coating could only be achieved at this value. Changing the $\mathrm{pH}$ value either way affects the coating formation which generates tensile stress in the coating and the improvement in power loss reduction gets reduced. Table II highlights the elements present in the coating at different $\mathrm{pH}$ values. The cobalt content in the coating increased as the $\mathrm{pH}$ was increased and reached a maximum of $60-62 \%$ by weight for a $\mathrm{pH}$ of 9 . On the other hand, nickel content decreased. The results were in agreement with [26]. The saturation magnetization of cobalt $(167 \mathrm{emu} / \mathrm{g})$ was much higher than that of nickel (54 emu/g) so, increasing cobalt content would result in better soft magnetic properties. The amount of phosphorus remains relatively unchanged except for the coating with a $\mathrm{pH}$ of 9.4 where sodium was introduced in the coating and the compressive stress from the coating reduces which may be the reason for the decrease in improvement of power loss at a value of 9.4.

7) Magnetic Domain Imaging and loss separation

To study the effect of coating on power loss, the domain images were recorded before and after coating the sample. The magnetic domain imaging clearly shows the narrowing of domains after coating with Co-Ni-P. The average domain width in the rectangular box in figure 10 for the uncoated sample was $0.73 \mathrm{~mm}$ as compared to $0.48 \mathrm{~mm}$ for the Co-Ni-P coated sample. The narrowing of domain width decreases the anomalous loss. The anomalous loss is directly proportional to velocity of the domain wall. As the domain width decreases the walls have to travel a shorter distance within the same time so the velocity of the wall decreases[5].

The model used here for loss separation was proposed by Ionel et. al [15] . The core loss equation (2a) is

$\mathrm{W}=\mathrm{k}_{\mathrm{h}} \mathrm{fB}^{\alpha}+\mathrm{k}_{\mathrm{e}} \mathrm{f}^{2} \mathrm{~B}^{2}+\mathrm{K}_{\mathrm{a}} \mathrm{f}^{1.5} \mathrm{~B}^{1.5}$

Where

$\mathrm{W}$ is the total loss, $\mathrm{k}_{\mathrm{h}} \mathrm{fB}^{\alpha}$ is the hysteresis loss component, $\mathrm{k}_{\mathrm{e}} \mathrm{f}^{2} \mathrm{~B}^{2}$ is the eddy current and $\mathrm{K}_{\mathrm{a}} \mathrm{f}^{1.5} \mathrm{~B}^{1.5}$ is the anomalous loss component. The loss per cycle is given by $\mathrm{W} / \mathrm{f}=\mathrm{k}_{\mathrm{h}} \mathrm{B}^{\alpha}+\mathrm{k}_{\mathrm{e}} \mathrm{fB}^{2}+\mathrm{K}_{\mathrm{a}} \mathrm{f}^{0.5} \mathrm{~B}^{1.5}$

Equation (2b) can be compared to a quadratic equation of the type $\mathrm{a}+\mathrm{bx}+\mathrm{cx}^{2}$ as shown in (2c) assuming $\mathrm{k}_{\mathrm{h}}, \mathrm{k}_{\mathrm{a}, \text {, }} \mathrm{k}_{\mathrm{e}}$ and $\alpha$ are constants independent of frequency and magnetic flux density. The coefficients of $\mathrm{f}^{0.5}$ can be found by plotting a fitting curve. $\mathrm{W}=\mathrm{a}+\mathrm{bf}^{0.5}+\mathrm{cf}$ (2c)

Where $\mathrm{a}=\mathrm{k}_{\mathrm{h}} \mathrm{B}^{\alpha} \mathrm{b}=\mathrm{k}_{\mathrm{a}} \mathrm{B}^{1.5} \mathrm{c}=\mathrm{k}_{\mathrm{e}} \mathrm{B}^{2}$

The values were plotted over a range of frequencies from $10 \mathrm{~Hz}$ to $1000 \mathrm{~Hz}$ to get a good approximation of the fitting. The value of the correlation coefficient [28] $\mathrm{r}^{2}$ was 0.9997 and 0.99996 for the uncoated and Co-Ni-P coated samples respectively. Figure 11 shows the loss separation data for the uncoated and coated sample. It can be clearly seen from the graph that the coated sample shows large reduction in anomalous loss which was in agreement with the magnetic pattern viewer images.

8) $X$-ray Diffraction

The XRD result in figure 12 shows the uncoated, $35 \mathrm{~min}$ and 90 min coated sample. The diffusive broad peaks in the histogram confirms the amorphous or nanocrystalline nature of the coating. The peaks may be Co-P or Co-Ni-P. The sharp peaks that were observed correspond to $\alpha$-Iron and $\alpha$-IronCobalt $\left(\mathrm{Fe}_{0.3} \mathrm{Co}_{0.7}\right)$. The 110 reflection was shifted towards the lower angle in the coated sample as can be seen in figure 12 . 
Stress is introduced by the coating [22] which can expand the lattice of the substrate material.

From Bragg's law [29] the stress shift was interpreted. The shift in peaks towards a lower angle confirmed that the inter planer distance $d$ increases and hence compressive stress developed in the coating. An equivalent tensile stress acted on the grain-oriented electrical steel surface to compensate the compressive residual stresses due to which there was an improvement in magnetic properties.

\section{CONCLUSIONS}

An effective coating on grain oriented electrical steel provides sufficient tension and insulation to reduce the specific total loss and magnetostriction. In addition to that the magnetic activity and reduced thickness improves the stacking factor. An electroless deposition of Co-Ni-P was shown to provide an effective coating for electrical steels. The thickness of the coating was half the thickness of conventional coatings and being magnetic in nature, it further improves the stacking factor in the transformers to $98.83 \%$. The threshold value of magnetostriction was shifted by $1.8 \pm 0.20 \mathrm{MPa}$ towards left after coating the sample. The time period for the electroless deposition dictates the thickness of the coating and hence the power loss reduction. A reduction of power loss by $4-5 \%$ was observed for samples coated for 20 minutes as compared to a reduction of $9-11 \%$ for samples coated for 90 minutes duration. The increase in $\mathrm{pH}$ of the solution from 7.8 to 9.0 decreases the surface roughness of the coating which reduces the hysteresis loss. The domain structure was also narrowed which reduces the anomalous loss; hence the overall total loss for grain oriented electrical steel was reduced. It is suggested that these coatings could be scaled cost effectively to production material due to the simple auto-catalytic process.

\section{ACKNOWLEDGMENT}

This work was supported by Tata Steel RD\&T, Rotherham and Cogent Power Ltd., Newport.

\section{REFERENCES}

[1] T. Steven, A. Moses, J. Hall, and K. Jenkins, "The effect of precipitate size on magnetic domain behavior in grain-oriented electrical steels," Journal of Applied Physics, vol. 107, p. 09A307, 2010.

[2] J.-T. Park and J. A. Szpunar, "Effect of initial grain size on texture evolution and magnetic properties in nonoriented electrical steels," Journal of Magnetism and Magnetic Materials, vol. 321, pp. 1928-1932, 2009.

[3] H. Haiji, K. Okada, T. Hiratani, M. Abe, and M. Ninomiya, "Magnetic properties and workability of $6.5 \%$ Si steel sheet," Journal of Magnetism and Magnetic Materials, vol. 160, pp. 109-114, 1996.

[4] J. W. Shilling, "Domain Structure During Magnetization of Grian-Oriented 3\% $\mathrm{Si}-\mathrm{Fe}$ as a function of Applied Tensile Stress," Journal of Applied Physics, vol. 42, pp. 1787-1789, 15 Mach 1971.

[5] C. R. Boon and J. A. Robey, "Effect of domain-wall motion on power loss in grainoriented silicon-iron sheet," Proceedings of the IEEE, vol. 115, pp. 15351540, October 1968.
[6] K. Tone, H. Shimoji, S. Urata, M. Enokizono, and T. Todaka, "Magnetic Characteristic Analysis Considering the Crystal Grain of Grain-Oriented Electrical Steel Sheet," IEEE Transactions on Magnetics, vol. 41, pp. 1704-1707, May 2005.

[7] B. N. Filippov, S. V. Zhakov, and Y. G. Lebedev, "Influence of domain structure on some dynamic properties of fferomagnets " IEEE transactions on magnetics, vol. MAG-15, pp. 1849-1854, November 1979.

[8] R. Langman, "The Effect of Stress on the Magnetization of Mild Steel at Moderate Field Strengths," IEEE Transactions on Magnetics, vol. MAG-21, pp. 1314-1320, 1985.

[9] T. Yamamoto and T. Nozawa, "Effects of Tensile Stress on Total Loss of Single Crystals of $3 \%$ Silicon-Iron," Journal of Applied Physics, vol. 41, pp. 2981-2984, June 1970.

[10] T. Olding, M. Sayer, and D. Barrow, "Ceramic solgel composite coatings for electrical insulation," Thin Solid Films, vol. 398-399, pp. 581-586, 2001.

[11] H. Yamaguchi, M. Muraki, and M. Komatsubara, "Application of CVD method on grain-oriented electrical steel," Surface \& Coatings Technology, vol. 200, pp. 3351-3354, 2006.

[12] X. D. He, X. Li, and Y. Sun, "Microstructure and magnetic properties of high silicon electrical steel produced by electron beam physical vapor deposition," Journal of Magnetism and Magnetic Materials, vol. 320, pp. 217-221, 2008.

[13] G. O. Mallory and J. B. Hajdu, "Electroless Plating Fundamentals \& Applications," American electroplaters and surface finishers society, vol. chapter 4, pp. 121-122, 1990.

[14] P. Chivavibul, M. Enoki, S. Konda, Y. Inada, T. Tomizawa, and AkiraToda, "Reduction ofcoreloss in non-oriented(NO) electrica lsteel by electrolessplated magnetic coating," Journal of Magnetism and Magnetic Materials, vol. 323, pp. 306-310, 2011.

[15] D. M. Ionel, M. Popescu, S. J. Dellinger, T. J. E. Miller, R. J. Heideman, and M. I. McGilp, "On the Variation With Flux and Frequency of the Core Loss Coefficients in Electrical Machines," IEEE transactions on industry applications, vol. 42, pp. 658-667, 2006.

[16] D. H. Kim, K. Aoki, and O. Takano, "Soft Magnetic Films by Electroless Ni-Co-P Plating," Journal of the electrochemical society, vol. 142, pp. 3763-3767, 1995.

[17] P. Anderson, "Measurement techniques for the assessment of materials under complex magnetising conditions," Electrical review, vol. 87, pp. 61-64, 2011.

[18] P. I. Anderson, A. J. Moses, and H. J. Stanbury, "Assessment of the Stress Sensitivity of Magnetostriction in Grain-Oriented Silicon Steel " IEEE Transactions on Magnetics, vol. 43, pp. 34673476, 2007.

[19] R. J. Taylor and J. A. Watt, "Magnetic pattern viewer," US Patent, vol. 5034754 A, 1991. 
[20] A. A. Aal, A. Shaaban, and Z. A. Hamid, "Nanocrystalline soft ferromagnetic $\mathrm{Ni}-\mathrm{Co}-\mathrm{P}$ thin film on Al alloy by low temperature electroless deposition," Applied Surface Science, vol. 254, pp. 1966-1971, 2008.

[21] A. K. Sharma, M. R. Suresh, H. Bhojraj, H. Narayanamurthy, and R. P. Sahu, "Electroless Nickel Plating on Magnesium Alloy," Metal Finishing, vol. 96, pp. 10, 12, 14, 16, 1998.

[22] J. Y. Song and J. Yu, "Residual stress measurements in electroless plated Ni-P films," Thin Solid Films, vol. 415, pp. 167-172, 2002.

[23] K. Parker and H.Shah, "The stress of electroless nickel deposits on beryllium," Journal of the Electrochemical Society, vol. 117, pp. 1091-1094, 1971.

[24] N. Fenineche, A. M. Chaze, and C. Coddet, "Effect of $\mathrm{pH}$ and current density on the magnetic properties of electrodeposited Co-N-P alloys," Surface and Coatings Technology, vol. 88, pp. 264-268, 1996.

[25] T. Homma, J. Shiokawa, Y. Sezai, and T. Osaka, "In situ analysis of the deposition process of electroless CoNiP perpendicular magnetic recording media," Electroechemical society proceedings, vol. 95, p. PV 181, 1996.

[26] K. S. Lew, M. Raja, S. Thanikaikarasan, T. Kim, Y. D. Kim, and T. Mahalingam, "Effect of $\mathrm{pH}$ and current density in electrodeposited $\mathrm{Co}-\mathrm{Ni}-\mathrm{P}$ alloy thin films," Materials Chemistry and Physics, vol. 112, pp. 249-253, 2008.

[27] K. Toshiya Wada, T. N. Munakata, and T. T. Kitakyushu, "Method for producing a super low watt loss grain oriented electrical steel sheet," US Patent, vol. 3,932,236, January 13, 1976.

[28] R. A. Fisher, "Frequency Distribution of the Values of the Correlation Coefficient in Samples from an Indefinitely Large Population," Biometrika, vol. 10, pp. 507-521, May 1915.

[29] W. L. Bragg, "The Diffraction of Short Electromagnetic Waves by a Crystal," Proceedings of the Cambridge Philosophical Society, vol. 17, pp. 43$57,1913$.

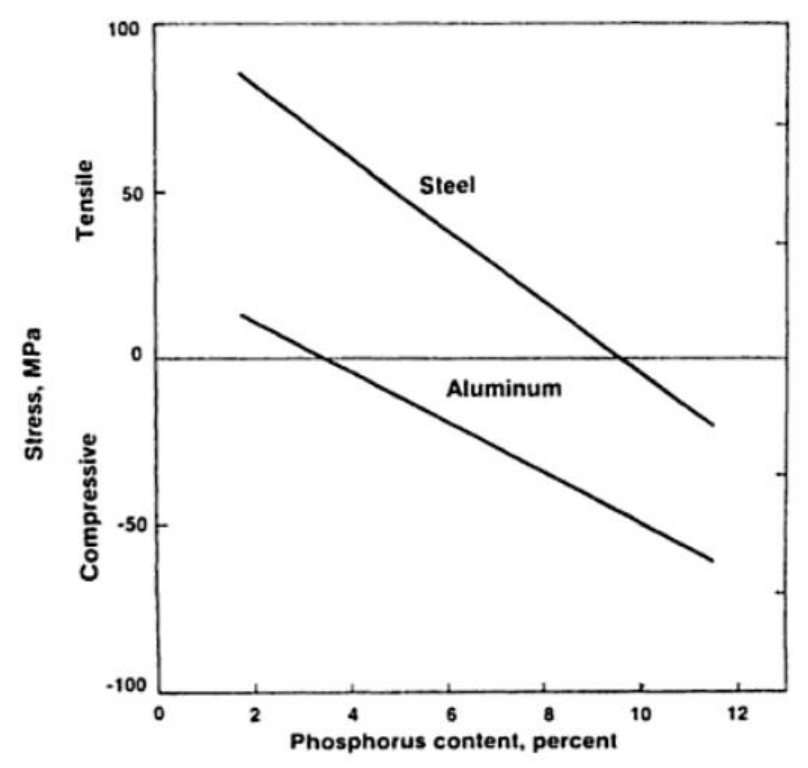

Figure 1. Relationship between phosphorus content and stress in the coating.
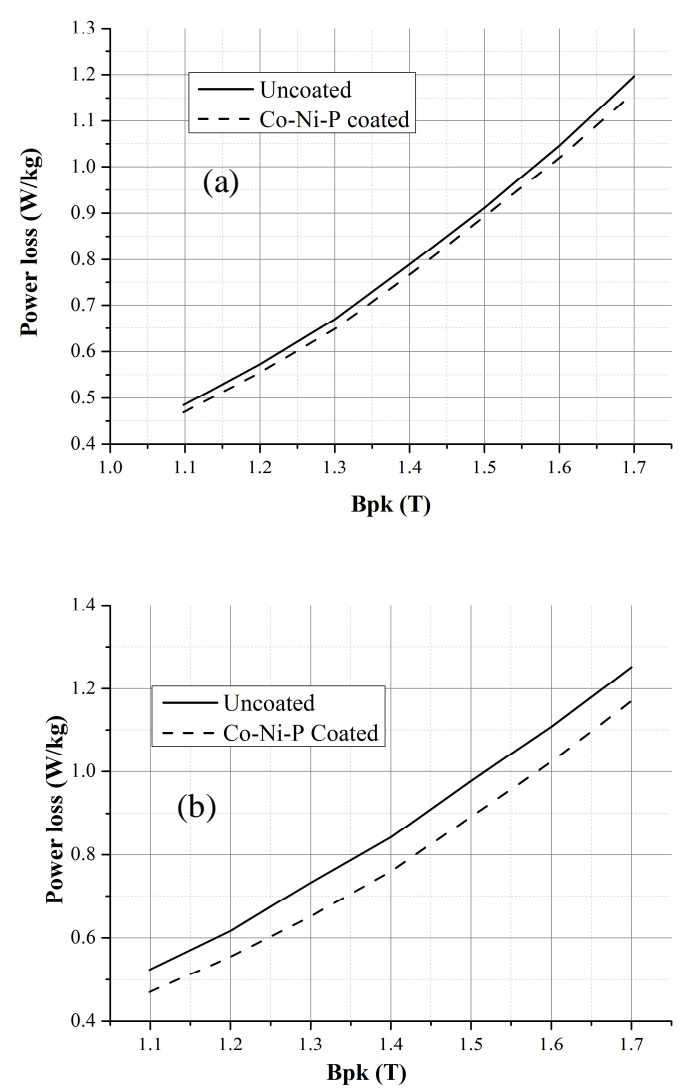

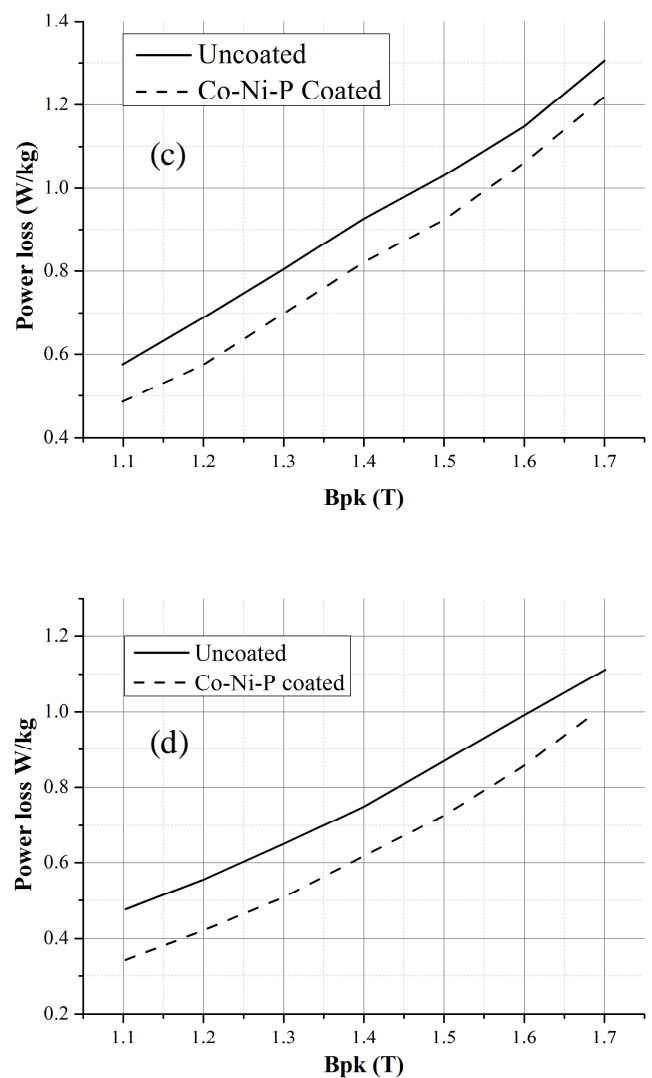

Figure 2.Power loss testing for the uncoated and Co-Ni-P coated for different times (a) $20 \mathrm{~min} \mathrm{(b)} 35 \mathrm{~min}$ (c) $50 \mathrm{~min}$ (d) $90 \mathrm{~min}$.

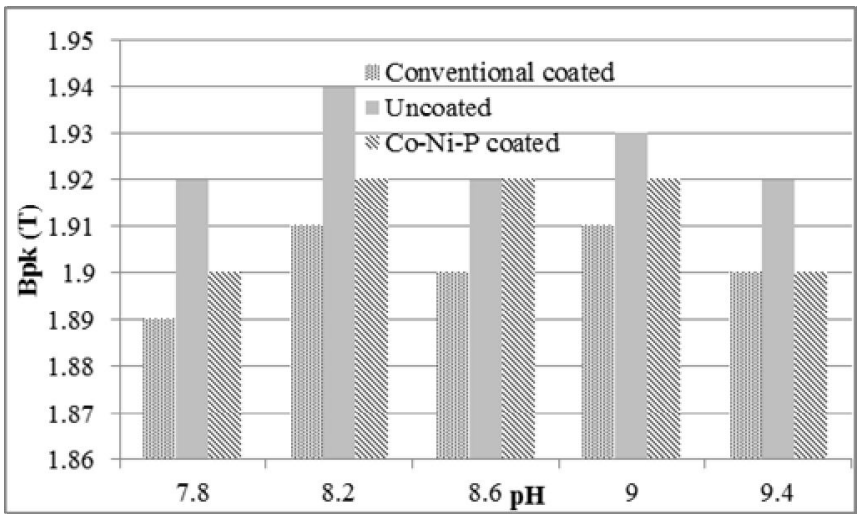

Figure 3.Bpk measured at magnetic field strength of $800 \mathrm{~A} / \mathrm{m}$ for different values of $\mathrm{pH}$.

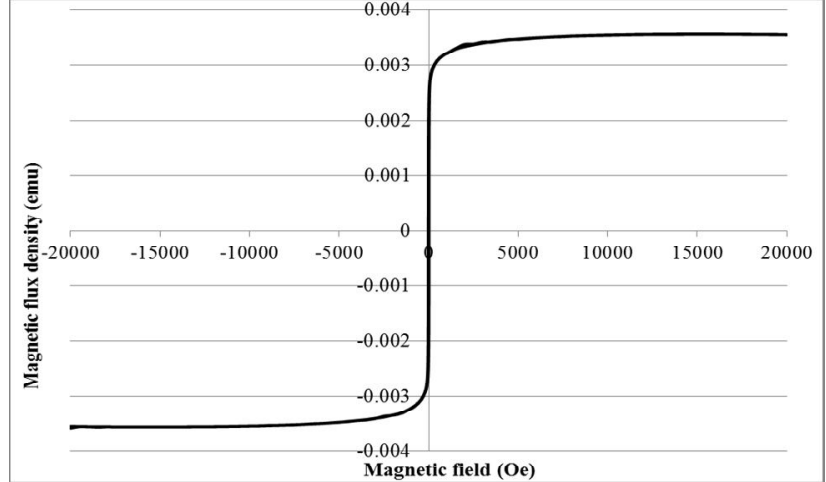

Figure 4. Magnetic flux density measured for Co-Ni-P coated at 9.0 .

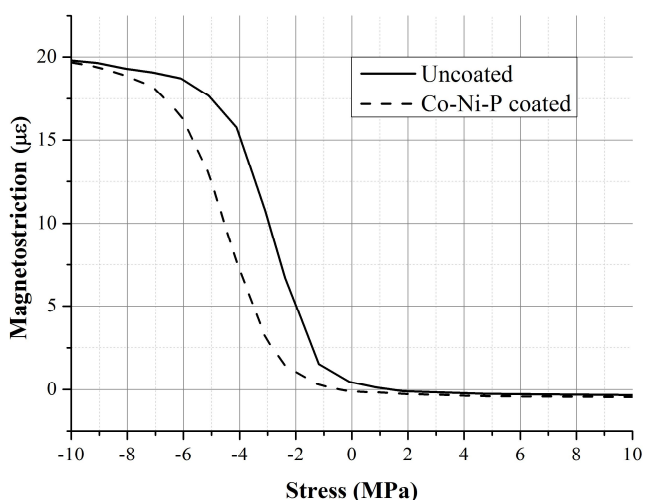

Figure 5.Magnetostriction v/s Stress for uncoated \& Co-Ni-P coated for $90 \mathrm{~min}$.

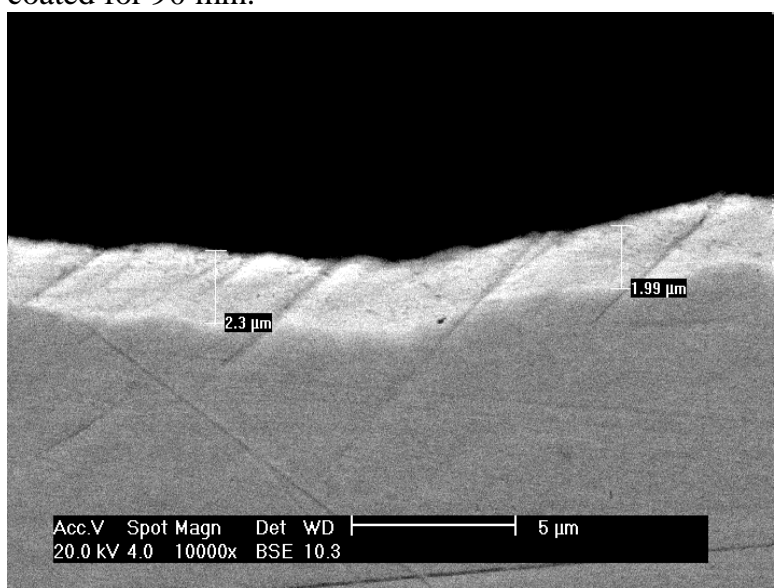

Figure 6.Cross section image of the substrate and the coating at $\mathrm{pH} 9$. 

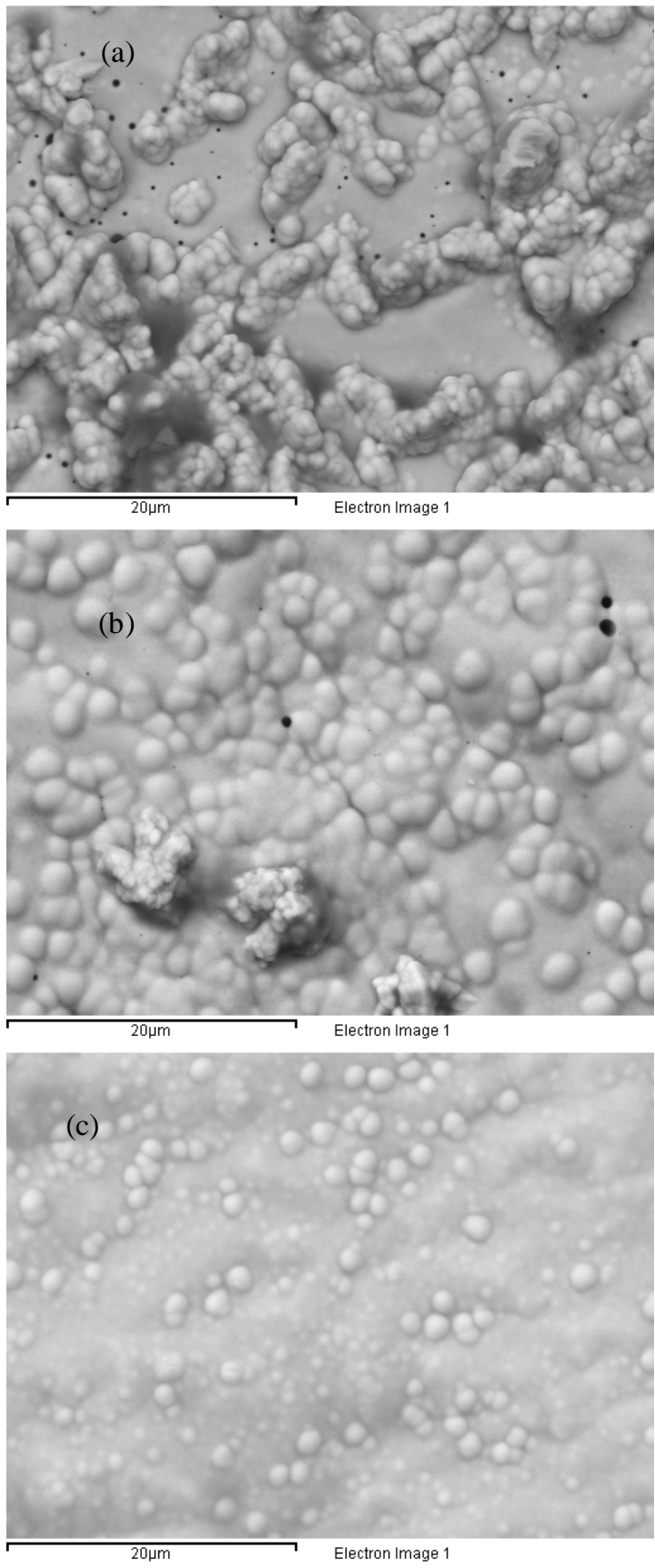

(d)

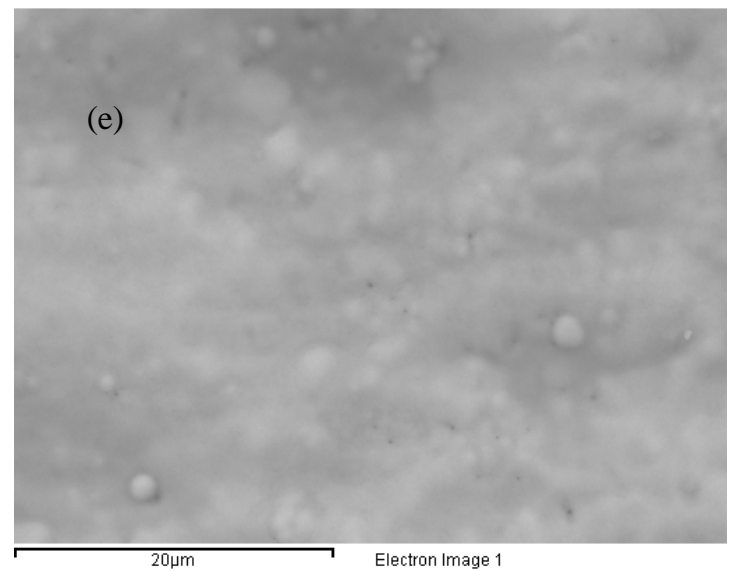

Figure 7.SEM images for the samples coated with different $\mathrm{pH}$ (a) 7.8 (b) 8.2 (c) 8.6 (d) 9 (e) 9.4 .

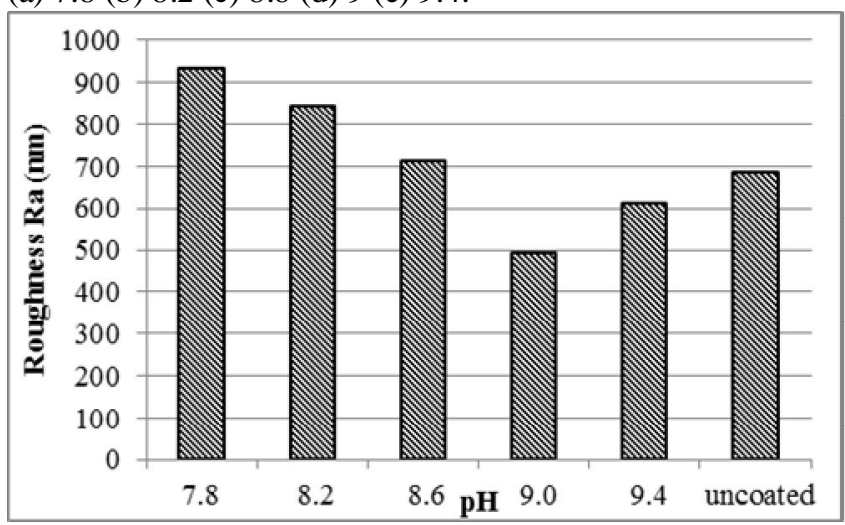

Figure 8. Talysurf surface roughness values Co-Ni-P coating at different $\mathrm{pH}$ values.

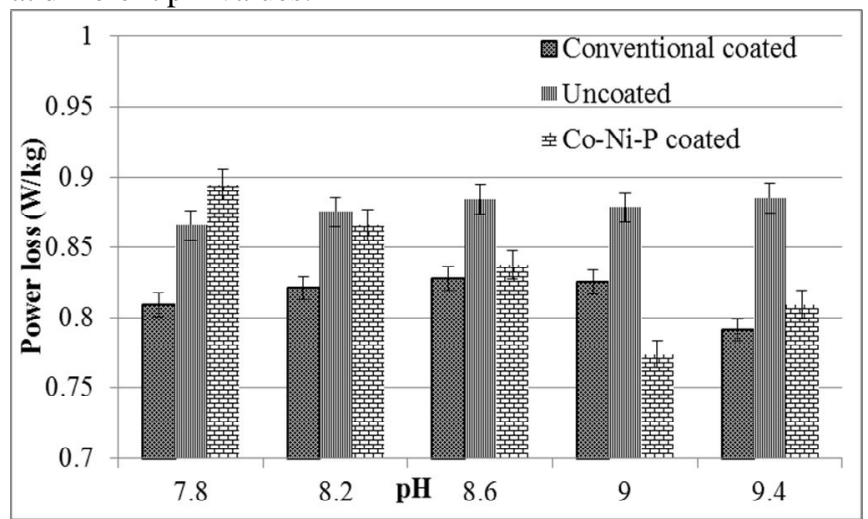

Figure 9.The effect of $\mathrm{pH}$ on power loss measured at 1.5T and $50 \mathrm{~Hz}$ frequency. 


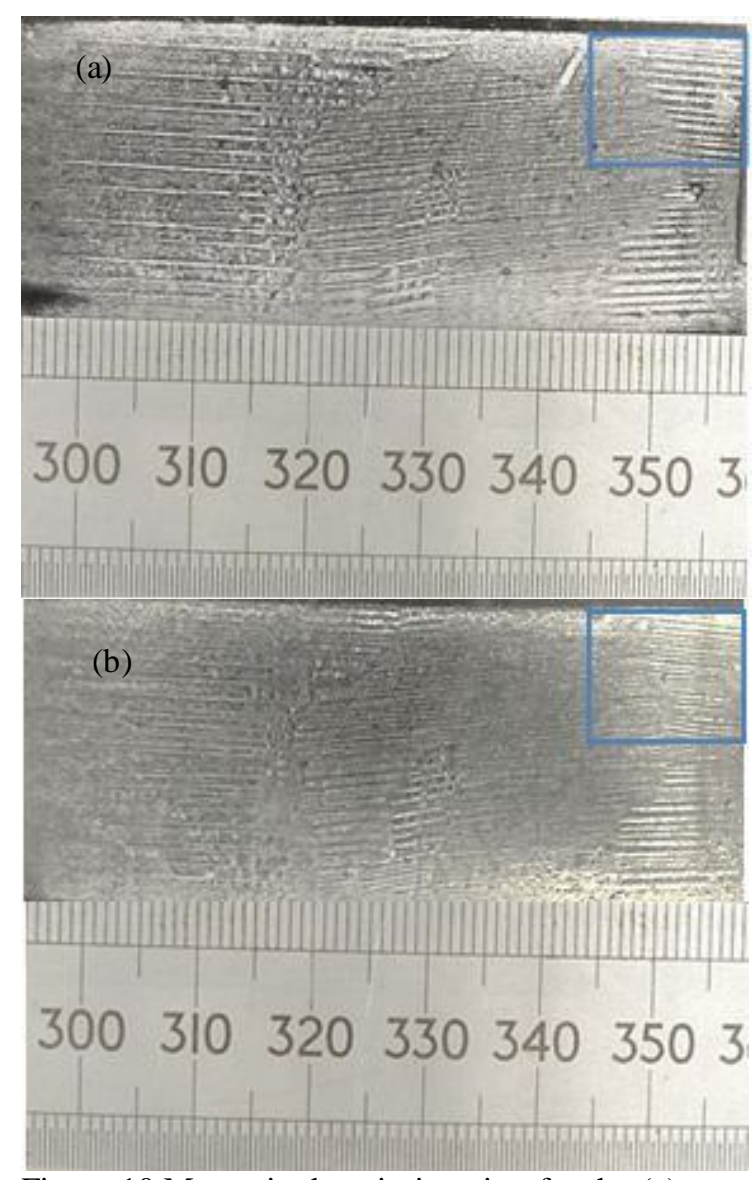

Figure 10.Magnetic domain imaging for the (a) uncoated and (b) Co-Ni-P at pH 9 coated sample.

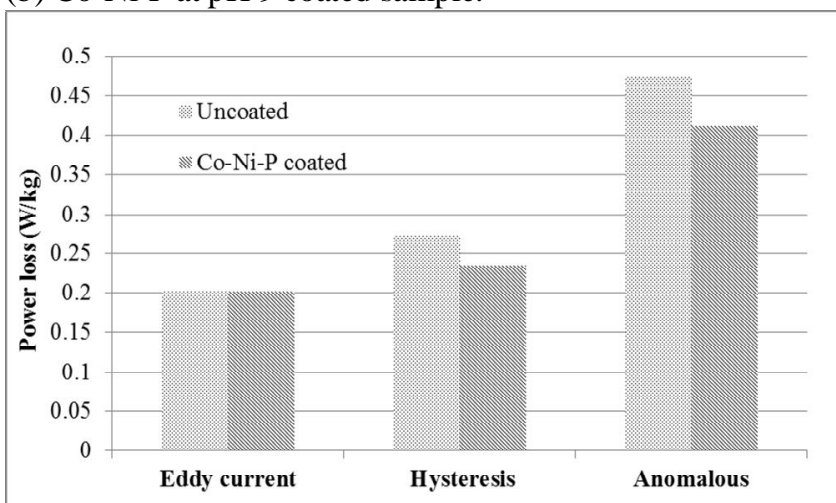

Figure 11.Loss separation at a magnetic flux density of $1.5 \mathrm{~T}$ and $50 \mathrm{~Hz}$ frequency for $\mathrm{Co}-\mathrm{Ni}-\mathrm{P}$ coated at $\mathrm{pH} 9$.

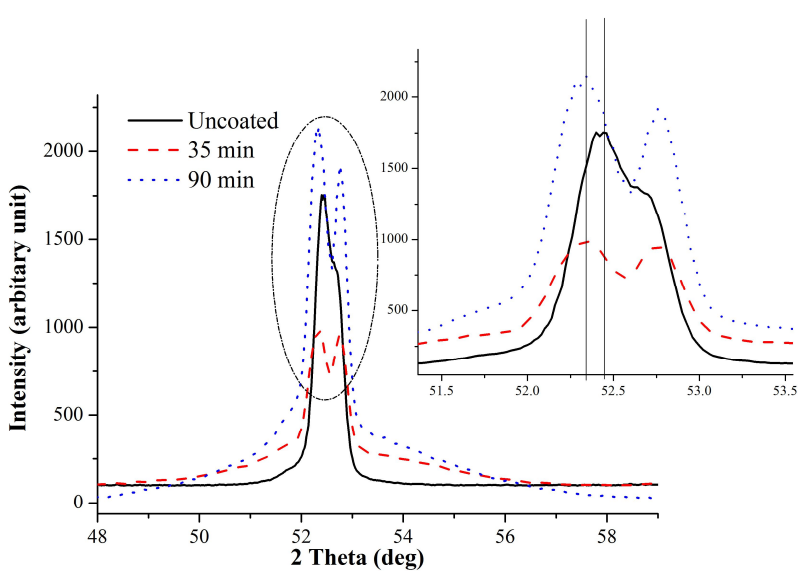

Figure 12.XRD of uncoated and Co-Ni-P coated samples at pH 9.

Table 1. Electroless plating bath conditions

\begin{tabular}{|l|l|}
\hline Composition & Grams/litre \\
\hline Nickel sulphate & 7.5 \\
\hline Cobalt sulphate & 15 \\
\hline Trisodium citrate & 50 \\
\hline Sodium hypophosphite & 25 \\
\hline Boric acid & 30 \\
\hline Temperature $60 \pm{ }^{\circ} 5$ & \\
\hline
\end{tabular}

Table 2. Elemental composition (weight \%) of the coating at different $\mathrm{pH}$ values.

\begin{tabular}{|c|c|c|c|c|}
\hline $\mathrm{pH}$ & Nickel\% & Cobalt\% & Phosphorus\% & Sodium\% \\
\hline 7.8 & $41-43$ & $48-50$ & $9-10$ & 0 \\
\hline 8.2 & $33-35$ & $54-56$ & $9-10$ & 0 \\
\hline 8.6 & $32-34$ & $55-57$ & $9-10$ & 0 \\
\hline 9.0 & $29-31$ & $60--62$ & $9-10$ & 0 \\
\hline 9.4 & $28-30$ & $58-60$ & $7-8$ & $4-5$ \\
\hline
\end{tabular}

